\title{
O desenvolvimento profissional do professor
}

\section{Professional teacher development}

\author{
Eliana Nardelli de CAMARGO* \\ Myrtes ALONSO**
}

\begin{abstract}
Resumo: Este trabalho explora relevantes aspectos relativos ao desenvolvimento profissional do professor. Nosso objetivo foi o de explicitar como os programas de formação continuada, dirigidos a professores podem contribuir para o aperfeiçoamento de suas práticas. Os temas abordados foram analisados pelos diversos autores indicados durante o curso da disciplina Formação e Desenvolvimento Profissional de Professores, em 2004, no Programa de Pós-Graduação em Educação: Currículo, na Linha de Pesquisa de Formação de Professores, da Pontifícia Universidade Católica de São Paulo (PUCSP). As respostas obtidas nesta pesquisa podem contribuir para que constatemos a presença ou ausência de elementos que acreditamos essenciais nesses programas. Consideramos que há mais de um caminho para se promover o desenvolvimento do professor, $\mathrm{e}$ sua escolha vai depender do perfil de professor que se pretende formar. Foram analisados três perfis, aos quais se relacionaram diferentes possibilidades de construção da autonomia. Embora objetivar a construção da autonomia profissional mostre-se fundamental, concluímos que o mais importante elemento a ser incluído nos referidos programas é a intensa preocupação com o desenvolvimento do auto-conhecimento do professor.
\end{abstract}

Palavras-chave: formação do professor, desenvolvimento profissional do professor, autonomia de professores

Abstract: This work examines important aspects of professional teacher development. Our aim was to present how on-going teacher educational programmes can contribute towards improvement in their practice. The subjects proposed were analyzed by several

\footnotetext{
* Mestre em Ciências da Comunicação pela Universidade de São Paulo - USP. Email: eliananardelli@atribuna.com.br

** Doutora em Educação pela Pontifícia Universidade Católica de São Paulo - PUCSP. Email: myrtes@uol.com.br

Olhar de professor, Ponta Grossa, 8(1): 79-89, 2005.
} 
of the authors suggested during the course on Professional Teacher Development as part of the Post-Graduate Course on Education: the Curriculum, research based on Teaching Background held at Pontifícia Universidade Católica de São Paulo (PUC-SP) in 2004. The results obtained in this research contribute towards finding out whether elements we believe to be fundamental in this kind of programme are missing or not. We consider there to be several ways of providing teacher development and this choice will depend on the teacher's profile that this program intends to develop. Three profiles were analysed, associating with each one different possibilities of developing teacher autonomy. Although developing autonomy seems to be fundamental, we concluded that the most important element to be included in the above-mentioned programmes is the concern with developing the teacher's self-knowledge.

Key words: teaching background, professional teacher development, teacher's autonomy

Esta reflexão traduz as conclusões a que pudemos chegar, após trajetória percorrida durante o curso de disciplina que abordou a temática em um programa de pós-graduação. Sua origem decorre do exame de dois programas de formação de professores, Letra e Vida e Teia do Saber, oferecidos pela Secretaria de Estado da Educação de São Paulo, e de subseqüente aprofun-damento das possíveis elaborações de programas dessa natureza. Da análise das necessidades dos programas de formação inicial e, enfaticamente, de formação continuada, emerge a questão que parece fundamental: o que difere um professor que, de fato, se profissionalizou, de outro, que ainda não se situou diante do amplo contexto que denominamos educação, chamando, para si, apenas a aplicação de técnicas elaboradas por outrem.

Para apresentar nossa conclusão, retomamos os aspectos considerados relevantes quando da elaboração de um programa de formação continuada que preencha os requisitos apontados pelos autores consultados, e a discussão de autonomia e profissionalização docente.

\section{FORMAÇÃO INICIAL E FORMA- ÇÃOCONTINUADA: REFLEXÕES INICIAIS}

A promulgação da nova Lei de Diretrizes e Bases da Educação Nacional-LDBEN 9.394/96 - e o financiamento da educação na América Latina, por organismos internacionais (Banco Mundial), aqueceram a reflexão acerca da formação do professor. $\mathrm{O}$ texto legal remete à necessidade $\mathrm{da}$ formação de todos os docentes em nível superior, seja pela universidade, seja pelos institutos superiores de educação, introduzindo uma medida

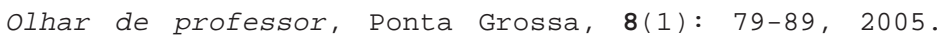


saneadora do despreparo dos professores em sua formação inicial. Em contrapartida, os organismos financiadores da educação em países em desenvolvimento asseguram, através de seus relatórios de avaliação, que os cursos de pedagogia não produzem efeito sobre os resultados da aprendizagem dos alunos. É o que encontramos em Mizukami (2002, p. 26), ao citar o que concluiu Lauglo (1997) do exame de relatório elaborado em 1995, pelo Banco Mundial, intitulado Prioridades e estratégias para educação:

A importância de um curso inicial em pedagogia é descartada com base em pesquisas em determinados países (Índia, Paquistão, Brasil), cujos dados levaram à conclusão de que tais cursos não produzem efeitos sobre os resultados da aprendizagem dos alunos, ou, simplesmente, que o conhecimento específico do conteúdo é mais importante para um ensino efetivo do que a pré-formação. (LAUGLO, 1997, p. 21).

Os debates estabelecidos evidenciaram, desde logo, que a formação inicial, importante deflagradora de um movimento individual, autônomo, de busca permanente da atualização, por parte dos professores, no decorrer de sua vida profissional, não contempla este aspecto. As Diretrizes Curriculares Nacionais para a formação de professores da educação básica centralizam sua discussão mais na emergência de novas estruturas organiza- cionais do que em experiências bem sucedidas, relacionadas a mudanças nos currículos dos cursos de pedagogia, por exemplo. Assim, o locus privilegiado da formação inicial, a universidade, é pulverizado, distribuindo-se também por instituições alternativas, agências promotoras de cursos de pequena duração. Ressalta-se, a partir de então, uma política educacional pautada na desvalorização da formação inicial de professores e, conseqüentemente, de sua profissão, passando-se a acentuar a formação continuada em serviço.

O novo modelo, desenvolvido nos últimos anos, apresentou-se poderoso para, quando muito, reformar o discurso dos educadores, sem acrescentar à sua prática qualquer mudança significativa. Essa realidade chamou a atenção dos profissionais da educação, já que os programas de formação continuada, dada a praticidade e a economia representadas por sua adoção, prometem permanecer. Os programas foram classificados e reclassificados de acordo com suas características e com fundamento em inúmeras avaliações, para se chegar, afinal, em uma concepção que reflete os mínimos a serem contemplados, quando de seu oferecimento. Desse trabalho surgiu este texto, que se propõe mais a apresentar conclusões do que a discuti-las. Para desenvolvê-lo, buscou-se o exame de diversos aspectos que compõem um programa de formação continuada, com um breve comentário a respeito de sua operacionalização. 


\section{AFORMAÇÃO DE PROFESSORES APARTIR DAESCOLA: UM NOVO DESAFIO}

Existe um certo consenso hoje de que as ações de formação desenvolvidas através de propostas gerais definidas por órgãos centrais do sistema de ensino não atendem às necessidades básicas das escolas, uma vez que não consideram o contexto de trabalho dos professores, onde deverão ser aplicadas as novas idéias trabalhadas nesses cursos. Essa tendência coloca hoje, para a escola, um enorme desafio: a formação dos seus professores com vistas não apenas ao seu desenvolvimento pessoal e profissional, mas também ao desenvolvimento da escola enquanto organização, em busca de um trabalho sempre melhor, mais condizente com as exigências de uma sociedade em mudança acelerada.

Qualquer proposta de formação deveria partir do seguinte questionamento: formar para quê? Onde pretendemos chegar com isso? Que professores desejamos ter em nossas escolas? Perguntas dessa natureza nos alertam para o fato de que todo processo de formação deve implicar mudanças nas pessoas e, por conseqüência, o desejo de realizar um trabalho em novas bases, desenvolvendo formas diferentes de conceber e praticar o ensino, mas essas idéias nem sempre se ajustam às condições existentes. Isso significa dizer que a organização escolar enquanto tal, as condições estruturais, as relações de trabalho, os sistemas de controle, em suma, o sistema existente deverão ajustar-se aos novos processos engendrados a partir das idéias incorporadas pelos professores. Caso contrário, qual a importância da formação realizada?

Para dar sentido ao processo de formação, portanto, é necessário contextualizá-lo, fazendo-se uma proposta a partir de uma realidade determinada e dos problemas e necessidades previamente diagnosticados.

Iniciemos, então, pelo diagnóstico, sem o qual nada se organiza. Quem o faz? As necessidades apontadas pelo diagnóstico são necessidades de quem? Para prosseguir, dadas as inúmeras possibilidades de respostas a essas duas questões, imaginemos que o diagnóstico relacione-se com o projeto político-pedagógico da instituição que vai desenvolver o programa de formação continuada.

Ora, se o perfil da instituição concorre para a tomada de decisões, então é em seu interior que tudo deve acontecer. Os participantes do programa não serão outros que não os envolvidos na construção e no desenvolvimento do projeto político-pedagógico daquela instituição, o que abrange mantenedor, direção, professores, alunos funcionários pais e comunidade. Nosso programa ampliouse demais? Tentemos, pois, restringilo aos educadores, já que se trata de formação continuada em serviço, e quem está em serviço, são os educa- 
dores. No entanto, já não é mais possível perder de vista que os demais atores exercem influência sobre o sucesso do programa, pois são eles que legitimam as ações da escola.

Com ou sem a participação dos diversos segmentos, surge um novo desafio: como agrupar os indivíduos? Já se sabe que agrupar indivíduos cujos interesses sejam convergentes constitui-se em facilitador para as discussões. Além disso, é preciso otimizar o tempo, já que a duração do programa é limitada. É preciso, então, estabelecer critérios para que os agrupamentos sejam positivos, o que só é possível através da formulação de objetivos. É preciso ter clareza a respeito do que se pretende alcançar com o desenvolvimento do programa. Novamente entram em cena o projeto político-pedagógico da escola e o diagnóstico que apontou as inconsistências na consecução dos objetivos e metas previstos pelo projeto.

Tendo-se clareza a respeito do cidadão que se pretende formar, através da escola, o que só é possível divisar a partir de uma incursão pela historicidade da instituição, passa a ser possível o estabelecimento dos objetivos. Bem verdade é que qualquer programa deve visar à instrumentalização de seus participantes para a autonomia, seja qual for o contexto em que o profissional venha a se inserir. Para tanto, é indiscutível a necessidade da percepção de si mesmo e dos conflitos de que se reveste sua atividade profissional, atri- buindo, aos mesmos, universalidade. Posto que se está diante de uma construção coletiva, já que a formação ocorre em grupos; de caráter individual, cada indivíduo é o alvo da própria formação e universal , simultaneamente, resta construir os caminhos a serem trilhados, sempre com a perspectiva de se evitar o que já se mostrou ineficaz.

O modelo de programa de formação pautado na reunião de indivíduos em torno de uma batuta pretensamente conhecedora de todas as realidades educacionais e poderosa para difundir técnicas a serem aplicadas em qualquer contexto, já mostrou suas limitações. Os professores que se permitiram aplicar tais técnicas logo perceberam a própria inaptidão para lidar com as diversas respostas que os alunos formulavam quando submetidos às atividades propostas. Assim, a aplicação de técnicas, longe de participar de um processo educativo, assumia perfil episódico e descolado da prática. Nesses tempos, o que se experimenta, então, é o caminho inverso: partir da reflexão sistemática sobre a prática para se chegar à teoria.

Resta saber que teoria é essa a que se vai chegar, sobretudo porque as práticas que se revelam podem não ilustrar qualquer teoria que sustente a construção de conhecimento. Daí a importância da partilha, do diálogo. É do confronto entre as diversas práticas e, naturalmente, entre as avaliações dos resultados obtidos através das práticas que se revela, 
desconstrói e constrói nova concepção de aprendizagem. Cabe retomar a já mencionada necessidade da tomada de consciência do professor a respeito de sua individualidade e da universalidade de seus problemas. É com essa consciência que as novas possibilidades de ação dialogarão. Assim, além de uma prática reflexiva interindividual, prevê-se, também, a ocorrência de uma prática reflexiva intra-individual.

Os modelos hodiernos que se flagram procuram contemplar, pelo menos em seus veículos de propaganda, os aspectos mencionados neste rápido ensaio. Contudo, durante sua execução, os programas acabam por se distanciar de seus propósitos iniciais. É bem verdade que, ao iniciarmos a nossa reflexão, evidenciamos a urgência de se destacar o projeto político-pedagógico das instituições que pretendem se beneficiar com a atualização de seus profissionais. E, talvez, seja igualmente verdadeiro, que o grande entrave à execução de todo e qualquer programa seja a definição exata de a quem seus resultados devem interessar. Se nossa política educacional é financiada e, portanto, definida por organismos externos, a resposta a essa questão não é sigilosa.

Mesmo que os contextos político e econômico desfavoreçam o florescimento de políticas públicas nacionais autônomas que assegurem - para além da letra da lei - o vigor de cada projeto político-pedagógico, que consideramos o deflagrador de qual- quer discussão acerca da emergência de novas práticas, não é mais possível esmorecer ao se tratar do desenvolvimento profissional do professor. Um programa de formação que promove a autonomia, inclui, indubitavelmente, a perspectiva do desenvolvimento profissional, para o qual se deve-se encaminhar uma nova reflexão.

\section{AUTONOMIA E PROFISSIONA- LIZAÇÃODOCENTE}

Autonomia profissional enquanto qualidade do ofício docente, não é um conceito fácil de construir. Para o seu entendimento, é necessário, inicialmente, considerar separadamente o que é autonomia e o que é profissional. O conceito de autonomia, com o qual temos habitualmente contato, opõe-se ao de heteronomia e diz respeito à faculdade de auto-governo, ou seja, à condução de si mesmo, com independência moral ou intelectual. No entanto, ao aplicarmos o conceito à docência, torna-se necessário relativizá-lo, entre outras razões, e sobretudo, porque há mais de uma concepção da profissão docente. Assim, para cada concepção, há igualmente uma concepção de autonomia. Quanto ao profissional, que, de acordo com um enfoque clássico, reflete uma coleção de determinadas características que particularizam sua profissão, também é preciso diferenciar os que se dedicam ao trabalho educativo. 
Entendendo ser o ensino uma prática social, que se realiza não somente através da ação docente, mas pela influência de contextos mais amplos, é preciso considerar que compreensão desses contextos é realizada pelos docentes, para que eles se manifestem adotando perfis diferenciados. Vale dizer que há formas diferentes de entender o trabalho de ensinar: "de onde procedem os valores educativos, e os compromissos morais; a relação existente entre a prática pedagógica e suas finalidades; as vinculações entre a prática e as exigências e condições de seu contexto social" (CONTRERAS, 2002,p. 191).

Levando-se em conta cada uma dessas interferências na prática docente, é possível diferenciar três concepções sobre a profissão de professor: o especialista técnico, o profissional reflexivo e o intelectual crítico. Para cada uma dessas concepções há um entendimento diferente das competências exigidas pela prática, bem como uma compreensão distinta do que seja a autonomia.

Para o especialista técnico, a prática profissional consiste basicamente "na solução instrumental de problemas, mediante a aplicação de um conhecimento teórico e técnico, previamente disponível, que procede da pesquisa científica" (CONTRERAS, 2002, p. 90). Pressupõe-se um sistema de raciocínio infalível que dispensa a participação do professor nos processo de tomada de decisão.

Para esse profissional, a autono- mia tende a ser ilusória, já que os problemas a serem enfrentados pelos docentes não são considerados em sua singularidade: parecem todos prédefinidos. Tal concepção sugere ser possível determinar com precisão onde se quer chegar, desconsiderando dilemas e incertezas. Tratase de uma tendência reducionista que dispensa a intervenção criativa do professor. A concepção de autonomia limita-a à de uma concessão, ou seja, a "liberdade" é concedida - ou imposta - para que o professor aplique tão somente soluções encontradas por outrem.

Contrapondo-se ao especialista técnico, situa-se o profissional reflexivo, para quem as regras técnicas e os cálculos não são suficientes para dar conta da diversidade de situações com que se deparam os docentes em suas rotinas. Entendendo que a "prática cotidiana está normalmente assentada em um conhecimento tácito, implícito, sobre o qual não exercemos um controle específico (idem, 2002), e que utilizamos esse conhecimento rotineiramente, mesmo sem que isso nos seja consciente, o profissional reflexivo reconhece o conhecimento, não como um dado anterior à ação, mas como inerente a ela. E é sobre essa mesma ação que ele se propõe a refletir, para reconduzi-la mais adequadamente (SHÖN, 1983, p. 338). O acúmulo do enfrentamento de problemas idênticos somado à criação de novas ações para a resolução de problemas inéditos, habilitam o profissi- 
onal reflexivo (Stenhouse, 1985). O professor é o pesquisador da própria ação (ELLIOTT, 1989), podendo fazer, desse seu trabalho, emergirem novas teorias.

Nesse caso, evidencia-se que, se no processo educativo as situações são particulares e exigem para cada uma a sua resposta exclusiva, é impossível que instâncias alheias determinem o que deve ser realizado. Por outro lado, é impossível ignorar que a educação desenvolve-se em um contexto social, do qual a comunidade participa com anseios e expectativas relacionadas ao tema, que podem ou não coincidir com os dos professores. É preciso então que se estabeleça o diálogo social e público, a fim de se tentar a conciliação entre as perspectivas para a função da escola e os valores existentes socialmente. $\mathrm{Na}$ construção do profissional reflexivo, não se inclui a perspectiva de transformação ante um mundo estrati-ficado, desigual e injusto; só se consideram exigências institucionais e sociais. Assim sendo, a concepção de autonomia passa a incluir não só a responsabilidade moral individual, mas também o equilíbrio entre a independência de juízo e a responsabilidade social.

A concepção do intelectual crítico está ligada à idéia de autoridade emancipadora (GIROUX, 1993), que deve promover, além da aprendizagem, uma luta coletiva por liberdade, igualdade e democracia. Assim, o compromisso docente amplia-se, passando a incluir um saber crítico e uma atuação mobilizadora que vise a uma transformação social. Para tanto, é imprescindível "o desenvolvimento de uma linguagem que identifique as injustiças sociais e uma linguagem da imaginação que auxilie a considerar aqueles aspectos da vida pública que apresentam possibilidades não realizadas" (id ibid, p. 382). Essa atuação implica parceria, e, portanto, sensibilidade aos valores da comunidade, o que se opõe ao corporativismo, via de regra entendido como profissionalismo. Além disso, para empreender essa luta contra os mecanismos opressores da sociedade, os professores devem ter claros referenciais políticos e morais. Todavia, o fato de permanecerem "presos" em suas salas de aula nem sempre permite a eles formular esses referenciais.

A autonomia, para a referida concepção de profissional, é entendida como um processo de construção da emancipação coletiva, possibilitada pela consciência crítica e pela linguagem, através das quais se superam as distorções ideológicas, assumindo-se responsabilidade pela transformação das condições institucionais e sociais.

Mesmo que se busque simplificar o conceito de autonomia profissional, relacionando-a às diversas concepções de profissionais da educação, sua abordagem ainda não se constitui em tarefa simples. No entanto, a idéia de reflexão crítica acrescenta uma via respiratória à questão. Refletir cri- 
ticamente significa colocar-se no contexto de uma ação, na história da situação, participar de uma atividade social e ter uma determinada postura diante dos problemas (KEMMIS, 1987). Isso inclui a crítica das estruturas institucionais, os limites impostos por elas à prática docente, e a decorrente compreensão dos valores e significados ideológicos implícitos, com vistas ao desenvolvimento de um papel profissional específico que abrange tanto a idéia de libertação pela educação quanto a de transformação das condições de trabalho e das práticas educativas e sociais. Embora a força dessa busca resida na união de grupos que admitam um ideal coletivo, o que de per si parece impossível (HABERMAS, 1984), ainda é preciso considerar que todo conhecimento é inacabado e parcial, no sentido de que projeta os interesses de uma parte sobre os de outras, o que se tem chamado de mito repressivo (ELLSWORTH, 1989).

Entretanto, há que se ampliar os horizontes utópicos, em busca de um conceito universal de autonomia. Para isso, é preciso entendê-la como o resultado de emancipação, concebendo-a não como um atributo, mas como um exercício, uma qualidade circunstancial desenvolvida reflexivamente através das relações sociais pautadas no diálogo, na negociação e no equilíbrio de posições. Se é papel das instituições democráticas propor a cultura que desejam ensinada, igualmente é papel do professor permanecer sensível às demandas sociais, para influir no estabelecimento dessa mesma cultura. Para a construção da autonomia ainda concorre a consciência da própria insuficiência, como parâmetro para a convivência com os outros.

Frente ao modelo neo-liberal vigente, que credita às escolas a responsabilidade pela mudança qualitativa, na oferta de ensino, adotando como princípios a autonomia e a descentralização, a atividade do professor passa a não se circunscrever à sala de aula. Isso lhe confere maiores responsabilidades educativas, ainda que não detenha meios para tanto, pois as circunstâncias em que o trabalho é desenvolvido permanecem as mesmas. A autonomia conferida às escolas não é política; relaciona-se somente à gestão; portanto, o que os profissionais da educação herdaram, na verdade, foi a chamada liberdade negativa (CARR, 1991).

Apesar da ênfase recair, em conseqüência da adoção do modelo neoliberal, sobre a competitividade individual, estimulada pelo lucro, os paradoxos que se instalam no interior das novas discussões incluem algum alento. Um ganho potencial é o fato de que as escolas devem pensar em si mesmas, estabelecendo suas funções e seus caminhos, o que pode significar a perpetuação de um fórum que conte "com maior lucidez por parte dos professores para interpretar os sinais das políticas e das práticas geradas nas escolas para assim avaliar e con- 
duzir tais práticas em direções mais educativas e mais justas" (CONTRERAS, 2002, p. 268). Outro paradoxo que pode favorecer a escola coloca-a em situação de grande vulnerabilidade aos conflitos sociais, os quais, ao eclodirem, minam a moral de quem nela convive. Para resistir a mais essa pressão, é recomendável a auto-avaliação (Simons, 1995) como uma experiência de aprendizado da própria escola sobre sua realidade. Uma vez públicos os debates sobre os problemas enfrentados pela escola, torna-se possível um processo de aprendizagem social através da participação da comunidade no enfrentamento de problemas referentes ao ensino e aos propósitos da educação.

A auto-avaliação constitui, sem dúvida alguma, um poderoso instrumento de aperfeiçoamento das instituições, desde que exercida com competência e objetividade, e que tome por base critérios estabelecidos coletivamente, sem qualquer preocupação de ocultar os fatos e os resultados indesejáveis. Esse processo, entretanto, requer maturidade das pessoas envolvidas, da própria instituição e, muitas vezes, necessita de orientação e apoio de especialistas. De qualquer forma, a conquista da autonomia passa por um processo de amadurecimento político e social para o qual concorre a auto-avaliação.

Assim, a autonomia, além de abarcar as considerações já tecidas a seu respeito, face a essa realidade, "não consiste em isolamento ou abandono dos professores ou das escolas à própria sorte, mas na concepção das relações entre professores e sociedade sob outras bases (as da constituição comunitária), de forma que os vínculos não sejam de natureza burocrática nem mercadológica, mas política e pessoal" (CONTRERAS, 2002, p. 269).

Todas as considerações anteriores nos levam a acreditar que as comunidades de aprendizagem constituem uma excelente estratégia para o desenvolvimento da autonomia, por permitirem que as pessoas exercitem a sua liberdade pessoal e as suas capacidades de reflexão e criação em ambientes heterogêneos e estimuladores, o que pode ser relevante para o desenvolvimento profissional do professor.

\section{CONSIDERAÇÕES}

Diante de um quadro complexo que hoje se propõe para a análise, em relação à formação do professor, seria arriscado adotar posições reducionistas que sugiram, novamente, a criação de fórmulas mágicas para a solução de todos os problemas relacionados ao tema. Assim mesmo, aventuramo-nos, nesta conclusão, a nos posicionarmos em favor de acentuado favorecimento de ações que promovam a autonomia do professor, entendendo que sua construção decorre de processo de auto-avaliação.

Anteriormente à construção da autonomia, localizamos o auto-co- 
nhecimento, como o ponto de partida para a construção do profissional, independentemente da área em que venha a atuar. Frente a um mercado de trabalho conturbado, em que a profissiona-lização acaba por se descaracterizar, quando do preenchimento de postos de serviço, visto que não há colocações garantidas para todas as profissões, os indivíduos abraçam as oportunidades que lhes surgem, independentemente de sua formação inicial. Por outro lado, a achatamento dos salários acabou por nivelar profissionais das mais diversas áreas de atuação. A crescente procura pelo magistério pode significar que a gratificação salarial dos que optam por essa carreira já não esteja tão distante do que se oferece a profissionais de outras áreas. Considerados esses dois aspectos, introduzimos um terceiro, que acreditamos definitivo para o sucesso de uma escolha profissional: a satisfação pessoal. Daí pautarmos nossa conclusão também na antiga máxima socrática "Conhece-te a ti mesmo", ousando afirmar que qualquer programa de formação, seja ela inicial ou continuada, que não inclua a possibilidade do autoconhecimento, está fadado à reprodução de indivíduos pouco capazes para construírem um projeto de vida que contemple, entre tantos outros planos, o de sua profissionalidade.

\section{REFERÊNCIAS}

CONTRERAS, J. A autonomia de professores. São Paulo: Cortez, 2002.

CRÓ, M. L. Formação inicial e contínua de professores/educadores: estratégias de intervenção. Porto: Porto Editorial, 1988.

GARCIA, C. M. A formação de professores: novas perspectivas baseadas na investigação sobre o pensamento do professor. In: NÓVOA, A. (Org.). Os professores e sua formação. Lisboa: Dom Quixote, 1995.

GOMEZ, A. P. O pensamento prático do professor: a formação do professor como profissional reflexivo. In: NÓVOA, A. (Org.). Os professores e sua formação. Lisboa: Dom Quixote, 1995.

IMBERNÓN, F. Formação docente e profissional: formar-se para a mudança e a incerteza. São Paulo: Cortez, 2004. (Coleção Questões da Nossa Época, v. 77)

MIZUKAMI, M. G. N. et al. Escola e aprendizagem da docência: processos de investigação e formação. São Carlos: EdUFSCar, 2002.

SHÖN, D. A. Formar professores como profissionais reflexivos. In NÓVOA, A. (Org.). Os professores e sua formação. Lisboa: Dom Quixote, 1995.

SHULMAN, L. S. Communities of learners \& communities of teachers. Monographs of Mandel Institute, [s.d.].

Encaminhado em 15/03/05

Aceito em 25/04/05 